L. C. Stene $\cdot$ P. M. Thorsby $\cdot$ J. P. Berg $\cdot$

K. S. Rønningen - D. E. Undlien - G. Joner •

Norwegian Childhood Diabetes Study Group

\title{
The relation between size at birth and risk of type 1 diabetes is not influenced by adjustment for the insulin gene (-23Hphl) polymorphism or HLA-DQ genotype
}

Received: 19 January 2006 / Accepted: 31 March 2006 / Published online: 12 May 2006

C) Springer-Verlag 2006

\begin{abstract}
Aims/hypothesis: Associations have been described between higher birthweight and increased risk of type 1 diabetes, and of insulin (INS) and human leucocyte antigen $(H L A)$ genotypes that protect against diabetes with larger size at birth. We studied simultaneously the effects of size at birth, INS and HLA genotypes on the risk of type 1
\end{abstract}

Members of Norwegian Childhood Diabetes Study Group, see Appendix

Electronic Supplementary Material Supplementary material is available for this article at http://dx.doi.org/10.1007/s00125006-0292-6

L. C. Stene $(\bowtie) \cdot$ K. S. Rønningen

Division of Epidemiology,

Norwegian Institute of Public Health,

P.O. Box 4404, Nydalen,

NO-0403 Oslo, Norway

e-mail: lars.christian.stene@ffhi.no

Tel.: +47-23-408176

Fax: +47-23-408252

L. C. Stene $\cdot$ P. M. Thorsby $\cdot$ J. P. Berg $\cdot$ G. Joner

Diabetes Research Centre,

Aker and Ullevål University Hospitals,

Oslo, Norway

P. M. Thorsby · J. P. Berg

Hormone Laboratory,

Aker University Hospital, Faculty Division

Aker University Hospital, University of Oslo,

Oslo, Norway

D. E. Undlien

Institute of Medical Genetics,

Faculty Division Ullevål University Hospital,

University of Oslo,

Oslo, Norway

D. E. Undlien

Department of Medical Genetics,

Ullevål University Hospital,

Oslo, Norway

G. Joner

Department of Paediatrics, Ullevål University Hospital,

Oslo, Norway diabetes to test whether the relation between size at birth and risk of type 1 diabetes would be strengthened after adjustment for INS and HLA genotypes. Subjects and methods: We designed a population-based case-control study in Norway with 471 cases of childhood-onset type 1 diabetes and 1,369 control subjects who were genotyped for the INS -23HphI polymorphism (surrogate for INS variable number of tandem repeats) and $H L A-D Q$ alleles associated with type 1 diabetes. Data on birthweight and other perinatal factors were obtained from the Medical Birth Registry of Norway by record linkage. Results: The data fitted a multiplicative model for the protective INS class III allele both within the INS locus and for the model with INS- and $H L A-D Q$-conferred risk of type 1 diabetes. We found no overall significant association between weight or head circumference at birth and the risk of type 1 diabetes, and adjustment for INS and HLA genotype did not influence this result. There was also no evidence for association of INS or $H L A$ with size at birth among control subjects. Conclusions/ interpretation: In contrast to suggestions from previous indirect studies, direct adjustment for INS and $H L A$ genotypes did not lead to a stronger relation between birthweight and the risk of type 1 diabetes.

Keywords Diabetes in childhood - Epidemiology/ genetics - Genetics of type 1 diabetes · Human - Pregnancy

Abbreviations ESM: Electronic supplementary material . INS: insulin gene - VNTR: variable number of tandem repeats

\section{Introduction}

Type 1 diabetes is a result of immune-mediated destruction of the pancreatic beta cells, but the factors initiating the destructive process are largely unknown [1]. There is evidence for the involvement of both genetic and nongenetic factors in this development. The two quantitatively most important genetic susceptibility loci influencing the risk of type 1 diabetes are the $H L A$ class II region and the 
insulin gene (INS) [2]. Several $H L A-D Q$ and $-D R$ alleles and genotypes are associated with risk and protection to different degrees [3], and the INS variable number of tandem repeats (VNTR) class I or its surrogate marker, the -23HphI A allele, has consistently been found to confer increased risk of type 1 diabetes [4, 5]. Accumulating evidence suggests that environmental factors may play a role early in life [6] and that there is an effect of size at birth and other perinatal factors on the risk of type 1 diabetes, generally of relatively small magnitude [7-11]. Several large-scale studies have found a high birthweight to be associated with a modest but statistically significant increase in the risk of childhood-onset type 1 diabetes [8, $9,11]$, although other, predominately smaller studies have not found a significant association [e.g. 7, 12]. The mechanism by which INS VNTR class III (or the linked $-23 \mathrm{HphI} \mathrm{T}$ ) allele reduces the risk of type 1 diabetes has been hypothesised to be via increased thymic expression of insulin during fetal and/or postnatal life [4]. INS polymorphisms may also affect fetal growth via a variety of pathways, including differential expression of $I G F 2$, although fetal pancreatic insulin expression is only moderately affected by allelic variation at the INS VNTR [4]. Some studies of children without diabetes have indicated that type 1 diabetes-protective alleles at the INS and HLA loci are associated with larger size at birth [1316], suggesting that any positive association between size at birth and the risk of type 1 diabetes may be attenuated by allelic variation at these loci. If so, the association between size at birth and the risk of type 1 diabetes should be strengthened after statistical adjustment for variation at these loci.

We therefore aimed to assess directly whether the odds ratio for the relation between size at birth and type 1 diabetes would be strengthened after adjustment for the INS -23HphI polymorphism and $H L A-D Q$ genotypes, regardless of whether an association existed before adjustment. Secondary objectives were to assess the joint effects of $H L A-D Q$ and INS polymorphism on the risk of type 1 diabetes, associations of INS and HLA with size at birth in the general population, and the role of birth order in these relations.

\section{Subjects and methods}

Study design

We designed a population-based case-control study in Norway, using cases of type 1 diabetes diagnosed before age 15 years between 1997 and 2000 and control children in the same age group randomly selected from the official population registry. All children were born between 19851999 and aged 1-15 years at the time of data collection [17]. Fifty-six per cent of controls and $73 \%$ of cases participated, with similar participation rates among regions, sexes and age groups [18]. DNA was collected using mailed mouth swabs and extracted as previously described [19]. Information on perinatal factors was obtained from the Medical
Birth Registry of Norway [20] by record linkage and additional data were collected using questionnaires mailed to the families [17]. Written informed consent was obtained from all participants, and the regional ethics committee and the Norwegian Data Inspectorate approved the study. After exclusion of children not born in Norway, twins, and children whose mother had diabetes during pregnancy, a total of 471 cases and 1,369 controls had complete data on INS, HLA and size at birth.

\section{Genotyping}

For both HLA and INS genotyping, cases and controls were genotyped at the same time, and laboratory personnel were blinded to the status (case or control) of the DNA samples. $H L A$ genotyping was performed using sequence-specific PCR identifying $H L A-D Q A 1^{*} 02, D Q A 1^{*} 03, D Q A 1^{*}$ 05, HLA-DQB1*0201, DQB1*0201/0302, DQB1* $0302 / 3, D Q B 1 * 0303, D Q B 1 * 0602, D Q B 1 * 0603 / 7$ and $D Q B 1^{*} 0301 / 4$, as previously described $[21,22]$. $D Q A 1$ $D Q B 1$ haplotypes were determined based on known linkage equilibria. Samples identified as $D Q A 1^{*} 05$ $D Q B 1^{*} 0201 / X(D Q 2 / X)$ were typed for additional alleles to determine whether they were homozygous for $D Q 2$ using PCR and allele-specific lanthanide (III) chelatelabelled probes in streptavidin-coated microtitration wells according to the manufacturer's protocol (Perkin-Elmer Life Sciences, Turku, Finland). Individuals were categorised in four groups based on HLA type: (1) protective: at least one $H L A-D Q B 1^{*} 0602$ allele; (2) high risk: $D Q A 1 * 03-D Q B 1 * 0302 / D Q A 1 * 05-D Q B 1 * 0201$ (DQ8/ $D Q 2)$; (3) moderate risk: $D Q 2 / D Q 2, D Q 8 / D Q 8$ or $D Q 8 /$ $X$, where $X$ represents alleles/haplotypes not defined above; and (4) all other genotypes $(X / X, D Q 2 / X)$, which were regarded as a neutral reference category for the purpose of this study, although this latter category includes genotypes with some variation in risk.

The INS -23HphI polymorphism (surrogate for INS VNTR) was genotyped in two independent laboratories. One laboratory used a TaqMan assay (Applied Biosystems, Foster City, CA, USA), run on an ABI 7900 HT Fast Realtime PCR system (Applied Biosystems). The other laboratory used RFLP analysis as previously described [23], but using nested PCR. Discrepant results were re-run in both laboratories and resolved or excluded. Additional details on genotyping are available from the authors. We refer to the -23HphI A (risk) allele as (VNTR) class I and the $\mathrm{T}$ (protective) allele as class III [4].

\section{Data analysis}

We used logistic regression analysis to assess associations of size at birth, INS and HLA genotypes with type 1 diabetes, including likelihood ratio tests of multiplicative interactions, and we used ANOVA and linear regression to assess associations of INS and HLA genotypes with size at birth among control children. A two-sided $p$ value less than 
0.05 or a $95 \%$ CI excluding the null value (1.00 for the odds ratio) was taken as indicating statistical significance.

\section{Power}

Based on previous results [9], we assumed for the prestudy power analyses a logit-linear model for the risk of type 1 diabetes according to birthweight in four groups, and that the crude odds ratio for birth weight of $4,000 \mathrm{~g}$ or greater vs $<2,500 \mathrm{~g}$ is 1.6 . We hypothesised that the odds ratio would increase to 1.8 after adjustment for INS and HLA genotype. This scenario would provide $81 \%$ power to detect a significant association between birthweight and type 1 diabetes with 500 cases and 1,500 controls. Under a recessive model (INS class III or I/III vs I/I), the use of 1,500 control subjects provides $90 \%$ power to detect significant differences in birthweight and head circumference if the true difference is $89 \mathrm{~g}$ and $0.27 \mathrm{~cm}$, respectively.

\section{Results}

Perinatal factors were not significantly associated with type 1 diabetes, but there was a slightly lower risk for children whose mothers were better educated, as previously reported [17] (Electronic supplementary material [ESM] Table 1). The well-established effect of HLA on the risk of type 1 diabetes was confirmed; the distribution among the 471 cases was $8,83,208$ and 172 with protective, neutral, moderate-risk and high-risk genotypes, respectively, and
$412,619,281$ and 57, respectively, among the 1,369 controls (ESM Table 2). The effect of HLA was essentially similar after stratification by birth order, with no significant interaction (not shown).

The distribution of INS genotypes class III/III, I/III and I/ I was 15, 120 and 336 among cases and 111, 527 and 731 among controls. The INS data fitted a multiplicative odds model (gene dose model) very well, with a nearly two-fold decrease in the risk of type 1 diabetes per protective class III allele (ESM Table 2). The odds ratio for the class I/I genotype vs I/III or III/III was 1.75 for first-born children and 2.55 for second- and later-born children, but the interaction between birth order and INS was not significant $(p=0.11)$.

The odds ratio for INS class I/I vs I/III or III/III was very similar in all subgroups of $H L A$-associated risk, with no significant deviation from a multiplicative model for INSand $H L A$-conferred risk (ESM Table 3).

Association between size at birth and type 1 diabetes after adjustment for INS and HLA

There was a tendency for those with the lowest birthweight to have a higher risk of type 1 diabetes, but there was no overall significant association between birthweight and the risk of type 1 diabetes, and this was essentially not influenced by adjustment for INS, HLA or other potential confounders (Table 1). No significant interaction between birthweight and INS ( $p=0.83), H L A(p=0.62)$ or birth order

Table 1 Association between size at birth and risk of type 1 diabetes after adjustment for INS and HLA genotype using logistic regression

\begin{tabular}{|c|c|c|c|c|c|}
\hline \multirow[t]{2}{*}{ Birthweight (g) } & \multirow[t]{2}{*}{ Cases $(n=471)$} & \multirow[t]{2}{*}{ Controls $(n=1,369)$} & \multicolumn{3}{|l|}{ Odds ratio $(95 \% \mathrm{CI})$} \\
\hline & & & Unadjusted & Adjusted for $I N S$ and $H L A^{\mathrm{a}}$ & Additional adjustment $\mathrm{b}^{\mathrm{b}}$ \\
\hline$<2,500$ & $20(4.2 \%)$ & $22(1.6 \%)$ & $2.68(1.42,5.06)$ & $2.46(1.11,5.45)$ & $1.99(0.82,4.82)$ \\
\hline $2,500-2,999$ & $39(8.3 \%)$ & $107(7.8 \%)$ & $1.07(0.71,1.63)$ & $1.13(0.68,1.87)$ & $0.99(0.59,1.68)$ \\
\hline $3,000-3,499$ & $141(29.9 \%)$ & $416(30.4 \%)$ & 1.00 (reference) & 1.00 (reference) & 1.00 (reference) \\
\hline $3,500-3,999$ & $168(35.7 \%)$ & $518(37.8 \%)$ & $0.96(0.74,1.24)$ & $0.93(0.68,1.28)$ & $0.91(0.66,1.26)$ \\
\hline$\geq 4,000$ & $103(21.9 \%)$ & $306(22.4 \%)$ & $0.99(0.74,1.33)$ & $0.91(0.63,1.30)$ & $0.91(0.63,1.33)$ \\
\hline Trend $^{\mathrm{c}}$ & & & $0.982(0.962,1.002)$ & $0.979(0.955,1.004)$ & $0.987(0.960,1.015)$ \\
\hline Test for trend ${ }^{c}$ & & & $p=0.10$ & $p=0.08$ & $p=0.36$ \\
\hline \multicolumn{6}{|c|}{ Head circumference $(\mathrm{cm})$} \\
\hline$<33$ & $22(4.7 \%)$ & $38(2.8 \%)$ & $1.78(1.03,3.07)$ & $1.99(1.01,3.93)$ & $1.55(0.73,3.30)$ \\
\hline $33-34$ & $118(25.1 \%)$ & $326(23.8 \%)$ & $1.11(0.86,1.44)$ & $1.02(0.75,1.39)$ & $0.96(0.70,1.33)$ \\
\hline $35-36$ & $237(50.3 \%)$ & $729(53.3 \%)$ & 1.00 (reference) & 1.00 (reference) & 1.00 (reference) \\
\hline $37-38$ & $88(18.7 \%)$ & $261(19.1 \%)$ & $1.04(0.78,1.38)$ & $1.03(0.73,1.45)$ & $1.05(0.73,1.50)$ \\
\hline$\geq 39$ & $6(1.3 \%)$ & $15(1.1 \%)$ & $1.23(0.47,3.21)$ & $1.30(0.41,4.10)$ & $1.34(0.42,4.34)$ \\
\hline Trend $^{\mathrm{c}}$ & & & $0.943(0.880,1.010)$ & $0.952(0.875,1.035)$ & $0.980(0.895,1.073)$ \\
\hline Test for trend ${ }^{c}$ & & & $p=0.09$ & $p=0.25$ & $p=0.66$ \\
\hline
\end{tabular}

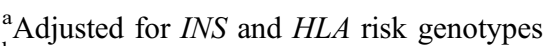

${ }^{\mathrm{b}}$ Adjusted for INS and HLA risk genotypes, plus gestational age, maternal age, birth order, maternal education and maternal smoking. Forty individuals were excluded because of missing data for at least one of the variables included as covariates (missing data: birth order, six cases, 11 controls; maternal education, seven cases, ten controls; maternal smoking during pregnancy, five cases, ten controls). Those with missing information for gestational age were included as a separate category

${ }^{\mathrm{c}}$ Trend in logit-linear risk model (logistic regression): odds ratio for type 1 diabetes per $100 \mathrm{~g}$ change in birthweight or per cm head circumference 
$(p=0.28)$ was observed. Very similar patterns were found for head circumference at birth (Table 1).

Association of INS and HLA with size at birth among population-based control children

There were significant associations of sex, gestational age, birth order and maternal smoking during pregnancy with size at birth (ESM Table 4). There was no significant association of INS genotype with size at birth (Table 2). No association was seen in either category of birth order (not shown).

Children carrying the type 1 diabetes-protective allele $H L A-D Q B 1 * 0602$ tended to be larger at birth, but the overall ANOVA test was not significant (Table 2), and this suggestive association was attenuated after adjustment for covariates (not shown). Inspired by a recent report [16], we also investigated $H L A-D Q B 1^{*} 0603$. The 170 control children carrying at least one $H L A-D Q B 1^{*} 0603$ allele had a mean birthweight of 3,594 g compared with 3,621 g for non-carriers $(p=0.52)$.

\section{Discussion}

We present for the first time a simultaneous analysis of the effect of size at birth and genetic factors on the risk of type 1 diabetes in a well-powered study. We were thus able to test directly whether the association between size at birth and type 1 diabetes is enhanced after adjustment for $I N S$ and HLA genotypes. Although previous indirect studies have provided circumstantial evidence for such enhancement [13-16], our direct test in the present report showed that this was not the case. The controls in the present study included only individuals who were not part of our pilot study [15], and thus provide an independent study of controls. Of the 471 cases, 175 (37\%) were also part of our previous cohort study based on linkage of registries without information on molecular genetic markers [9], whereas the rest of the cases in the present study had not been analysed previously.

Strengths of the present study include: (1) the inclusion of children drawn from registries with nearly complete population coverage; (2) linkage of registries via unique personal identification numbers; (3) the inclusion of a large number of type 1 diabetes cases; and (4) adjustment for a number of relevant covariates.

Among the study's limitations were: (1) we did not know the parental origin of the INS and HLA alleles; (2) we did not have postnatal growth data; and (3) participation was incomplete -a problem inherent in most clinical research. Although the response in our study was in line with that in many other studies in which biological specimens were collected [24], there is room for potential bias. The distribution of birthweight among the controls in the present study was shifted towards higher birthweights compared to the distribution of birthweights reported to The Medical Birth Registry of Norway [20] between 1985 and 1998 in which the mother did not have diabetes registered before or during pregnancy (e.g. $1.6 \%$ of participating controls had a birthweight $<2,500 \mathrm{~g}$ compared with $4.5 \%$ for all births in The Medical Birth Registry). Our controls also had mothers who were slightly older when giving birth compared with the background population. This may have been due to selection of participating controls whose mothers were more highly educated than average. Regarding maternal education, Vangen et al. [25] linked data from Statistics Norway on maternal education to The Medical Birth Registry of Norway for all births during 1986-1998, and found that 30.5\% of women had more than 12 years of education, $59.8 \%$ had 10 12 years of education, $8.4 \%$ had less than 10 years, and $1.3 \%$

Table 2 Associations of $H L A$ and INS polymorphisms with birthweight and head circumference at birth in 1,369 singleton control children born in Norway to mothers who did not have diabetes during pregnancy

\begin{tabular}{|c|c|c|c|c|}
\hline$H L A$ or $I N S$ genotype $^{\mathrm{a}}$ & Birthweight $(\mathrm{g})^{\mathrm{b}}$ & Test of difference ${ }^{c}$ & Head circumference at birth $(\mathrm{cm})^{\mathrm{b}}$ & Test of difference ${ }^{c}$ \\
\hline INS class $\mathrm{I} / \mathrm{I}(n=731)$ & $3,604(499)$ & $p=0.56$ & $35.30(1.451)$ & $p=0.70$ \\
\hline INS class I/III $(n=527)$ & $3,632(508)$ & & $35.38(1.538)$ & \\
\hline INS class III/III $(n=111)$ & $3,637(434)$ & & $35.33(1.435)$ & \\
\hline Coefficient for trend ${ }^{\mathrm{d}}$ & 21.5 & $p=0.31$ & 0.04 & $p=0.53$ \\
\hline Adjusted coefficient, trend ${ }^{\mathrm{d}}$ & 11.9 & $p=0.55$ & 0.007 & $p=0.91$ \\
\hline HLA DQB1*0602 $(n=412)$ & $3,659(488)$ & $p=0.15$ & $35.45(1.404)$ & $p=0.12$ \\
\hline$H L A X / X, D Q 2 / X(n=619)$ & $3,586(515)$ & & $35.28(1.542)$ & \\
\hline$H L A D Q 2 / 2,8 / X, 8 / 8(n=281)$ & $3,625(470)$ & & $35.25(1.444)$ & \\
\hline$D Q 8 / 2(n=57)$ & $3,615(497)$ & & $35.58(1.535)$ & \\
\hline
\end{tabular}

${ }^{\text {a }}$ Risk categories defined a priori: protective $=$ at least one $H L A-D Q B 1^{*} 0602$ allele; $D Q 8=D Q A 1^{*} 03-D Q B 1^{*} 0302 ; D Q 2=D Q A 1^{*} 05$ $D Q B 1 * 0201$

$X$, alleles/haplotypes not defined above

INS was genotyped at the $-23 \mathrm{HphI}$ polymorphism, where the A allele corresponds to the class I VNTR (risk) allele and the HphI T allele corresponds to VNTR class III

${ }^{\mathrm{b}}$ Data are mean (SD)

${ }^{\mathrm{C}}$ Overall one-way ANOVA test

${ }^{\mathrm{d}}$ Coefficient for trend based on linear regression (additive model), expressing increase in gram birthweight or centimeter head circumference per increase in class III allele. Test was the Wald test from the linear regression model. Adjusted coefficient is the same coefficient in the model also including sex, gestational age, birth order and maternal smoking during pregnancy 
had missing information. Corresponding results from our participating control children [18] were $37.1 \%$ ( $>12$ years), $54.3 \%$ (10-12 years), $7.3 \%$ ( $<10$ years) and 1.4\% (missing information). Despite slightly different calendar years and inclusion criteria, the above data indicate selection of children with higher birthweight and older and more highly educated mothers among our controls. Whether similar selection among our cases with type 1 diabetes occurred is unknown, but we can speculate that any such selection may have been weaker among case children, in whom there was a higher proportion of responses. If so, this may partly explain the lack of association of maternal age and birthweight with the risk of type 1 diabetes in the present study in contrast to our earlier reports $[9,10]$, in addition to the smaller sample size in the present study. On the other hand, there is little reason to suspect that the effect of molecular genetic markers on size at birth or on the relation between size at birth and type 1 diabetes should be influenced by any such potential bias, because it is hard to imagine that INS or HLA genotype should be strongly associated with behaviour directing participation in the study.

In relation to our secondary objectives, we note that the initial report of an association between the INS polymorphism and size at birth among children from the general population [13] has not been supported by recent reports [26-28]. A new study from the UK has indicated that the association between INS and size at birth primarily concerns head circumference, and was stronger for second and later children than for first-born children, presumably because first-born children experience more environmental restrictions on fetal growth than later-born children [14]. In our study, we found no indication of association between INS and size at birth in any group of birth order. In a previous study [15], we found a tendency for the $H L A$ $D Q B 1 * 0602$ allele, which is strongly protective against type 1 diabetes, to be associated with higher birthweight. We found a similar indication in the present data set, but this was not a significant or robust finding. A very large study from Sweden reported that $H L A-D Q B 1 * 0603$ (protective against type 1 diabetes) and the high-risk $D Q 2 / D Q 8$ genotype were associated with higher birthweight for gestational age [16], but we were unable to confirm this in our study. Consistent with other recent results [5], the protective class III alleles seemed to display a multiplicative allele dose effect, in contrast to the previous notion of a dominantly protective effect against type 1 diabetes [4].

From the present results it seems that, at least in our population, possible effects of INS and HLA on birthweight $[13,15,16]$ and of birthweight on the risk of type 1 diabetes $[9,11]$ are of too small a magnitude to allow clear findings of confounding or interacting effects on the risk of type 1 diabetes unless sample sizes are exceedingly large.

We conclude that, in contrast to indications from previous indirect studies, the relation between size at birth and type 1 diabetes was not influenced by adjustment for INS and HLA.
Acknowledgements L. C. Stene and G. Joner were supported by a grant from The Research Council of Norway (148359/330). Funding for L. C. Stene and G. Joner was also provided by the Norwegian Diabetes Association, Aker Diabetes Research Foundation, Novo Nordisk Fonden, Peter Möller AS, TINE Norwegian Diaries and Novo Nordisk Scandinavia. J. P. Berg and D. E. Undlien were supported by Eastern Regional Health Authorities. The latter was also supported by The National Programme for Research in Functional Genomics in Norway (FUGE) of the Research Council of Norway. We thank the staff at the Medical Birth Registry of Norway for their assistance with record linkage and the staff at the Biobank, Norwegian Institute of Public Health, for assistance with DNA extraction and genotyping. Specifically we thank H. E. Akselsen, M. Bjørnvold and K. Gervin at the Institute for Medical Genetics, Ullevål University Hospital, and V. Enge at Hormone Laboratory, Aker University Hospital, for help with genotyping.

Duality of interest The authors declare that they have no duality of interest.

\section{Appendix}

Members of the Norwegian Childhood Diabetes Study Group

Henning Aabech, Fredrikstad; Helge Vogt, Nordbyhagen; Knut Dahl-Jørgensen, Oslo; Kolbeinn Gudmundsson, Oslo; Jon Grøtta, Elverum; Halvor Bævre, Gjøvik; Ola Talleraas, Lillehammer; Kjell Stensvold, Drammen; Bjørn Halvorsen, Tønsberg; Kristin Hodnekvam, Skien; Ole Kr. Danielsen, Arendal; Jorunn Ulriksen, Kristiansand; John Bland, Stavanger; Dag Roness, Haugesund; Oddmund Søvik and Pål R. Njølstad, Bergen; Per Helge Kvistad, Førde; Steinar Spangen, Ålesund; Per Eirik Hæreid, Trondheim; Sigurd Børsting, Levanger; Dag Veimo, Bodø; Harald Dramsdahl, Harstad; Bård Forsdahl, Tromsø; Kersti Thodenius, Hammerfest.

\section{References}

1. Atkinson MA, Eisenbarth GS (2001) Type 1 diabetes: new perspectives on disease pathogenesis and treatment. Lancet 358:221-229

2. Concannon P, Erlich HA, Julier C et al (2005) Type 1 diabetes: evidence for susceptibility loci from four genome-wide linkage scans in 1,435 multiplex families. Diabetes 54:995-1001

3. Undlien DE, Lie BA, Thorsby E (2001) HLA complex genes in type 1 diabetes and other autoimmune diseases. Which genes are involved? Trends Genet 17:93-100

4. Pugliese A, Miceli D (2002) The insulin gene in diabetes. Diabetes Metab Res Rev 18:13-25

5. Barratt BJ, Payne F, Lowe CE et al (2004) Remapping the insulin gene/Iddm2 locus in type 1 diabetes. Diabetes 53:1884-1889

6. Leslie DG, Elliott RB (1994) Early environmental events as a cause of IDDM. Diabetes 43:843-850

7. Blom L, Dahlquist G, Nyström L, Sandström A, Wall S (1989) The Swedish Childhood Diabetes Study_-social and perinatal determinants for diabetes in childhood. Diabetologia 32:7-13

8. Dahlquist G, Patterson C, Stoltesz G (1999) Perinatal risk factors for childhood type 1 diabetes in Europe: the EURO DIAB Substudy 2 Study Group. Diabetes Care 22:1698-1702 
9. Stene LC, Magnus P, Lie RT, Søvik O, Joner G, The Norwegian Childhood Diabetes Study Group (2001) Birth weight and childhood onset type 1 diabetes: population based cohort study. BMJ 322:889-892

10. Stene LC, Magnus P, Lie RT, Søvik O, Joner G, The Norwegian Childhood Diabetes Study Group (2001) Maternal and paternal age at delivery, birth order, and risk of childhood onset type 1 diabetes: population based cohort study. BMJ 323:369-371

11. Dahlquist GG, Pundziute-Lyckå A, Nyström L (2005) Birthweight and risk of type 1 diabetes in children and young adults: a population-based register study. Diabetologia 48:1114-1117

12. Kyvik KO, Bache I, Green A, Beck-Nielsen H, Buschard K (2000) No association between birth weight and type 1 diabetes mellitus - a twin-control study. Diabet Med 17:158-162

13. Dunger DB, Ong KK, Huxtable SJ et al (1998) Association of the INS VNTR with size at birth. ALSPAC study team. Avon longitudinal study of pregnancy and childhood. Nat Genet 19:98-100

14. Ong KK, Petry CJ, Barratt BJ et al (2004) Maternal-fetal interactions and birth order influence insulin variable number of tandem repeats allele class associations with head size at birth and childhood weight gain. Diabetes 53:128-133

15. Stene LC, Magnus P, Rønningen KS, Joner G (2001) Diabetesassociated HLA-DQ genes and birth weight. Diabetes 50:2879-2882

16. Larsson HE, Lynch K, Lernmark B et al (2005) Diabetesassociated HLA genotypes affect birthweight in the general population. Diabetologia 48:1484-1491

17. Stene LC, Joner G, The Norwegian Childhood Diabetes Study Group (2004) Atopic disorders and risk of childhood-onset type 1 diabetes in individuals. Clin Exp Allergy 34:201-206

18. Stene LC, Joner G, The Norwegian Childhood Diabetes Study Group (2003) Use of cod liver oil during the first year of life is associated with lower risk of childhood-onset type 1 diabetes: a large, population based, case-control study. Am J Clin Nutr 78:1128-1134
19. Witsø E, Stene LC, Paltiel L, Joner G, Rønningen KS (2002) DNA extraction and HLA genotyping using mailed mouth brushes from children. Pediatr Diabetes 3:89-94

20. Irgens LM (2000) The Medical Birth Registry of Norway. Epidemiological research and surveillance throughout 30 years. Acta Obstet Gynecol Scand 79:435-439

21. Olerup O, Aldener A, Fogdell A (1993) HLA-DQB1 and -DQA1 typing by PCR amplification with sequence-specific primers (PCR-SSP) in 2 hours. Tissue Antigens 41:119-134

22. Cinek O, Koloušková S, Šnajderová M et al (2001) HLA class II genetic association of type 1 diabetes mellitus in Czech children. Pediatr Diabetes 2:98-102

23. Thorsby PM, Berg JP, Birkeland KI (2005) Insulin gene variable number of tandem repeats is associated with increased fat mass during adolescence in non-obese girls. Scand J Clin Lab Invest 65:163-168

24. Morton LM, Cahill J, Hartge P (2006) Reporting participation in epidemiologic studies: a survey of practice. Am J Epidemiol 163:197-203

25. Vangen S, Stoltenberg C, Johansen RE, Sundby J, StrayPedersen B (2002) Perinatal complications among ethnic Somalis in Norway. Acta Obstet Gynecol Scand 81:317-322

26. Lindsay RS, Hanson RL, Wiedrich C, Knowler WC, Bennett $\mathrm{PH}$, Baier LJ (2003) The insulin gene variable number tandem repeat class I/III polymorphism is in linkage disequilibrium with birth weight but not type 2 diabetes in the Pima population. Diabetes 52:187-193

27. Mitchell SM, Hattersley AT, Knight B et al (2004) Lack of support for a role of the insulin gene variable number of tandem repeats minisatellite (INS-VNTR) locus in fetal growth or type 2 diabetes-related intermediate traits in United Kingdom populations. J Clin Endocrinol Metab 89:310-317

28. Bennett AJ, Sovio U, Ruokonen A et al (2004) Variation at the insulin gene VNTR (variable number tandem repeat) polymorphism and early growth: studies in a large Finnish birth cohort. Diabetes 53:2126-2131 